\title{
Monitoring Important Bird Areas in Africa: towards a sustainable and scaleable system
}

\author{
LEON BENNUN ${ }^{1,3, *}$, PAUL MATIKU ${ }^{2}$, RONALD MULWA ${ }^{3}$, \\ SOLOMON MWANGI ${ }^{2}$ and PAUL BUCKLEY ${ }^{4}$ \\ ${ }^{1}$ BirdLife International, Wellbrook Court, Girton Road, Cambridge CB3 ONA, UK; ${ }^{2}$ Nature Kenya, \\ P.O. Box 44486, 00100 Nairobi, Kenya; ${ }^{3}$ National Museums of Kenya, P.O. Box 40658, 00100 \\ Nairobi, Kenya; ${ }^{4}$ Royal Society for the Protection of Birds, The Lodge, Sandy, Beds., SG19 2DL, \\ UK; *Author for correspondence (e-mail: leon.bennun@birdlife.org)
}

Received 20 June 2004; accepted in revised form 20 August 2004

Key words: Institutionalisation, Kenya, Key biodiversity area, Locally-based monitoring, Participatory monitoring, Site Support Group

Abstract. The need for effective global monitoring of biodiversity is clearer than ever, but our measurements remain patchy and inadequate. In the biodiversity-rich tropics, a central problem is the sustainability of monitoring schemes. Locally-based, participatory approaches show promise in overcoming this problem, but may not contribute effectively to monitoring at larger scales. BirdLife International's framework for monitoring Important Bird Areas (IBAs) in Africa is designed to be simple, robust and locally-grounded, but to produce scaleable results that can be compiled into national or regional indices. Focusing on key sites for bird conservation, identified according to standard criteria, the framework institutionalises monitoring in site management authorities and Site Support Groups (community-based organisations of local people working for conservation and sustainable development). A small, central monitoring unit co-ordinates the programme nationally, compiles, analyses and manages data, and provides feedback. 'Basic' monitoring (taking place at all sites) involves scoring of state, pressure and response trends using site information submitted on simple forms. 'Detailed' monitoring (taking place at a selected sub-set of sites) involves more intensive measurement of particular variables that relate to site management targets. IBA monitoring is now underway in at least 10 African countries, with implementation of the framework most advanced (thanks to a pilot project) in Kenya. The 2004 IBA monitoring report for Kenya provides extensive information on individual IBAs, plus indices for national trends in state, pressure and response, based on data from 49 out of 60 sites. The experience in Kenya shows that institutionalisation is vital, but takes considerable time and effort; that adequate co-ordination (including timely feedback) is key; and that participatory monitoring has many valuable benefits beyond the data collected. Further work is being undertaken to refine the process, improve its scientific underpinning, and strengthen the feedback loop from data and analysis to action on the ground.

\section{Introduction}

The world's leaders have agreed a target of significantly reducing, by 2010, the current rate of biodiversity loss at the global, regional and national levels (United Nations 2002). Effective monitoring of biodiversity seems to be needed more than ever. However, our measurement of trends in biodiversity remains remarkably patchy and inadequate (Balmford et al. 2003; Royal Society 2003). 
Especially in the biodiversity-rich tropics, monitoring schemes face an array of conceptual, logistical and political problems (Bennun 2001; Sheil 2001; Yoccoz et al. 2001). The most significant of these perhaps concerns sustainability. Schemes are often too elaborate and costly to be continued in the long-term (Bennun 2001; Danielsen et al. 2003), or fail to be adequately institutionalised (Poulsen and Luanglath 2005 (this issue)).

Locally-based, participatory monitoring has been proposed as one solution (Danielsen et al. 2003). Monitoring should be more sustainable when it involves very simple, inexpensive methods, put into effect by local communities or government staff (Danielsen et al. 2003; Gray and Kalpers 2005 (this issue); Topp-Jørgensen et al. 2005 (this issue)). Such approaches may also simplify and strengthen the link between data collection and effective local management action (see Andrianandrasana et al. 2005; Danielsen et al. 2005; Rijsoort and Jinfeng 2005; Uychiaoco et al. 2005 (this issue)).

Under the right circumstances, such schemes can be effective in strengthening local management of resources and dealing with threats to biodiversity (Danielsen et al. 2003). How useful are they, though, in contributing to biodiversity monitoring at larger scales, such as the national level? Here, local, participatory schemes have some obvious potential drawbacks. Biases in data collection are likely, especially where local communities design their own sampling regime. These may or may not be a big concern at the site level, but they can potentially have a distorting effect when combined into larger datasets. Simple approaches may sometimes be just too simple to provide meaningful data. Where no standard frameworks are applied, it may be hard to bring the results of different schemes together. This last difficulty reflects a more general disconnect between site-specific initiatives and global biodiversity monitoring (Saterson et al. 2004). However, the problem is likely to be especially acute for schemes that rely on simple, qualitative assessments or perceptions.

This paper outlines how BirdLife International has attempted to tackle these issues in developing a monitoring framework for Important Bird Areas (IBAs) in Africa. This framework is simple, robust and locally grounded, yet is designed to produce scaleable results that can be compiled into national, regional or global indices. Here we first give some brief background to the IBA programme and how it links with national institutions and local communities. We then outline the two-tier IBA monitoring framework for Africa and how it is intended to work. Implementation of the framework is examined using examples from a pilot project in Kenya. Finally, we summarise the lessons learned so far, and some issues still outstanding.

\section{Important Bird Areas and Site Support Groups}

BirdLife's Important Bird Area (IBA) programme aims to identify and conserve a network of the key sites for bird conservation around the world. Sites are identified nationally using a set of criteria agreed globally by the BirdLife 
Partnership ${ }^{1}$ (Fishpool and Evans 2000; BirdLife International 2004a). These are based on the presence of populations of bird species that are globally threatened, restricted in range, congregatory or characteristic (as an assemblage) of a particular biome. The Important Bird Area network is part (usually a very substantial part) of the larger set of key biodiversity areas, identified by extending similar criteria to other taxonomic groups (BirdLife International 2004a; Eken et al. 2005).

More than 1230 IBAs have already been identified and documented in Africa (Fishpool and Evans 2000). BirdLife Partners are now progressing the IBA programme through the stages of planning and priority-setting, conservation (involving recognition, safeguard, and resourcing) and monitoring (Bennun 2002; BirdLife International 2004a, b). This involves forming partnerships at the national and site level with Government institutions and other NGOs.

Encouraging and supporting the development of Site Support Groups (SSGs) is an important element of the approach. SSGs are community-based organisations of local people working for conservation and sustainable development in and around an IBA. SSGs have diverse origins and structures, but usually have an entirely local base and a large volunteer element. They can be seen as a means of building social capital (Pretty and Smith 2004) - a mechanism for empowering people to organise themselves and use their natural resources wisely. Over 60 SSGs are now active in at least 10 African countries (BirdLife International 2004b).

SSGs can contribute to site conservation in many ways. Their activities include, for example, running education and awareness programmes, building local recognition and pride for special wildlife, restoring and managing habitat, helping in patrolling and policing, implementing sustainable use projects, developing eco-tourism - and monitoring. Most fundamentally, SSGs can act as an entry point for wider community involvement in conservation and management of biodiversity.

BirdLife Partners recognise that SSGs are not appropriate for every IBA, and that working with these local groups is not always easy. They can require considerable support, especially early in their development. The role of the BirdLife Partner is to facilitate and guide (though not control) their growth and activities. This often requires training, the provision of basic equipment, making links to other supporters and to Government, help with marketing, planning and fund-raising, help in building their own governance - and, in case of a crisis, discreet but effective intervention. BirdLife Partners may channel project funds to SSGs, but the local groups remain autonomous and the relationship needs to be carefully managed to avoid dependency.

\footnotetext{
${ }^{1}$ The BirdLife International Partnership is a worldwide network of autonomous national conservation NGOs (Partners or Partners Designate), supported by a large grassroots membership. The network also includes BirdLife Affiliates, contacts within a particular geographical territory that are working towards becoming an established BirdLife Partner. For simplicity, in this paper 'Partner' is used to refer to BirdLife Partners, Partners Designates and Affiliates.
} 
There is no BirdLife Partner yet in many African countries. However, the IBA approach provides a set of tools for conservation (including the monitoring framework) that can be used by any organisation.

\section{A monitoring framework for African Important Bird Areas}

\section{History and aims}

Following a consultative development process, the BirdLife African IBA monitoring framework was endorsed by BirdLife's Council of the African Partnership in October 2002. Implementation began early the following year. In August 2003 BirdLife Partners from 11 African countries met to discuss progress and ways to overcome constraints (Arinaitwe 2003). Implementation is presently most advanced in Kenya, where capacity development has been supported by a pilot project, discussed further below.

The framework responded to the Partnership's needs for a monitoring system that was simple, robust, flexible, sustainable and able to provide useful information at a wide range of scales, from the individual site to the region as a whole. It also took into account the likely benefits (in awareness, engagement and effective follow-up) of directly involving those who live in and around IBAs. The IBA monitoring has two general aims: to assess how effectively BirdLife and others are conserving these key biodiversity areas, and to detect threats so they can be acted upon in good time.

BirdLife's IBA monitoring is the 'site' component of a larger framework that includes monitoring of species (the status of threatened birds) and of habitats (populations of representative common birds: BirdLife 2004a, and see Gregory et al. 2003; and Roberts et al. 2005 (this issue)).

\section{Indicators}

Any monitoring system should first set out the questions that it aims to answer. Sites qualify as IBAs because they hold populations of particular species of birds (often termed 'trigger species'). The questions of interest are therefore: how is the status of these populations changing? How are the pressures on these populations changing? What responses have been put in place to diminish these pressures? (Figure 1).

Answering these questions involves the measurement of appropriate indicators. For IBA monitoring, these must be relevant to the bird populations of interest. They should be feasible to measure and meaningful to interpret. They also should work at different spatial scales, so that the results for individual sites can be put together to demonstrate trends over larger areas. Since these indicators are focused on the trigger bird species, they may or may not give a good picture of trends in other important biodiversity at the site. Also, IBA 


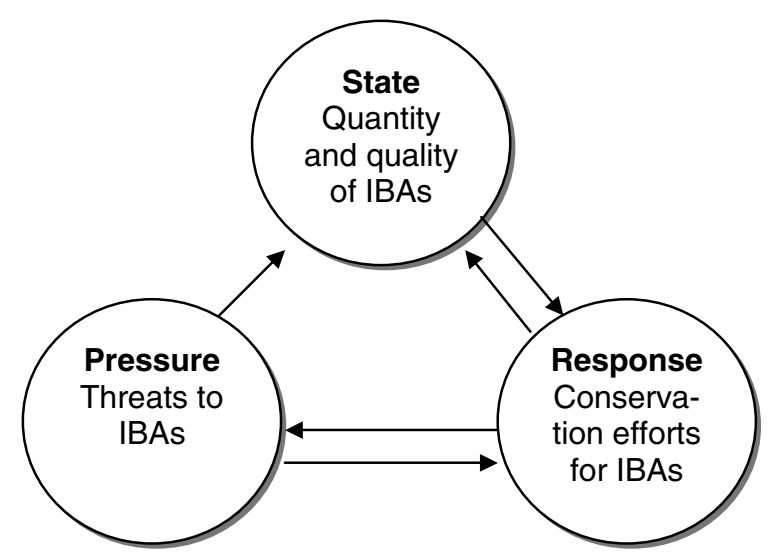

Figure 1. The pressure-state-response framework for Important Bird Area monitoring.

monitoring clearly does not tell us what is happening to particular species outside IBAs. However, IBAs constitute the most significant sites for their trigger species (and in particular include nearly all sites where globally threatened birds are regularly found). Thus, comprehensive monitoring across the relevant suite of IBAs gives a meaningful (if not absolutely complete) picture for a species as a whole.

\section{Monitoring design and set-up}

The IBA monitoring framework aims to keep the system as simple as it can be while still producing meaningful results. BirdLife Partners cannot possibly monitor every IBA themselves. It is crucial that other appropriate national and local institutions - especially those that have a site management mandate take ownership of the monitoring process and make it part of their routine work.

Other principles followed in the design and implementation of the framework include:

- Use straightforward indicators that are easy to assess, and robust yet inexpensive methods.

- As far as possible, build on and incorporate existing monitoring efforts (such as the African Waterbird Census; Dodman 1997).

- Make maximum use of volunteers and existing expert networks for collecting useful data.

- Work closely with local communities, to build monitoring from the bottom up and ensure that it is relevant to their needs.

- Target investment towards outreach, capacity development and co-ordination.

- Ensure a constant trickle of resources, avoiding the deluge and drought that characterise many externally-funded projects. 
- Link monitoring clearly to conservation action - and ensure a good balance between the two: monitoring is not an end in itself.

With 1230-plus IBAs in Africa, there is an obvious trade-off between the depth and the breadth of coverage. Producing national and regional indices requires broad coverage, which will necessarily be sketchy at many sites. However, adaptive management may well require more intensive collection of information. The framework balances depth and breadth by differentiating basic and detailed monitoring (see below).

Those carrying out monitoring, whether basic or detailed, at particular sites need to 'own' the process. Here, the IBA monitoring framework makes an important assumption: that the results of monitoring will be sufficiently useful to management authorities and SSGs that they are prepared to adopt this process and carry out the work. In the early stages of setting up an IBA monitoring programme, time and effort are needed to open institutional eyes to the benefits of monitoring, and the value of contributing to a wider, national scheme rather than setting up an independent process.

Effective national co-ordination of the IBA monitoring programme is required. So far, this role has most often been taken by a staff member (full- or part-time) or small team within the national BirdLife Partner. Co-ordination could be based in another national organisation, or a shared responsibility: in Kenya, for example, it is handled by a team based in both the National Museums of Kenya and the BirdLife Partner, Nature Kenya, linking with a set of monitoring focal points in other key institutions. However, this monitoring unit plays an important role in quality control, data compilation, management, analysis and reporting. It also helps to assess and monitor the monitoring process itself, and to make recommendations for improving and refining the system when needed.

To implement the wider IBA programme, many Partners have also set up socalled National Liaison Committees (NLCs). These regularly bring together the key institutions involved in IBA conservation and management. Where NLCs exist, they can play a useful role in high-level co-ordination of monitoring. They also constitute a valuable forum for discussing the monitoring results and ensuring appropriate responses at both the site and the policy level. The NLC also has an important role to play in refining the monitoring process as experience is gained.

The compiled information from monitoring feeds into a national IBA status report. The summary scores and notes are forwarded to the BirdLife secretariat for incorporation in the World Bird Database, allowing regional and global synthesis of trends.

\section{Basic monitoring}

Basic monitoring should ideally happen at all IBAs. It is based on a regular (preferably annual) review of information from the field or from remote sensing. 
For assessing changes in the state of IBAs, remote sensing holds much promise, and this is an area of active research. Remote sensing could allow quick assessment of changes in the boundaries or extent of a site. It may be particularly useful for monitoring the many sites that are difficult to access, or are in countries where on-the-ground IBA monitoring is not yet happening. However, remote sensing also has limitations. It may not always distinguish natural habitat from the surrounding matrix. It can provide only limited information on habitat degradation. And it says little about most kinds of pressures and responses. Also, site management authorities and local communities are rarely involved in collecting these kinds of data, so may feel little ownership over the process and limited interest in following up the results.

For these reasons, it is important that basic IBA monitoring uses an on-theground approach too. This works in a straightforward way. Information on particular IBAs is submitted on simple but structured forms by those with recent personal knowledge of the site. The forms are based on a set of indicators (Table 1) with space for scoring improvement or deterioration in each, and for textual commentary. These forms are used to collect data regularly, usually once a year, from Government or NGO staff and SSGs based at the site. The aim is to make form-filling a routine activity that is part of their annual workplan. The forms can also be used to capture valuable information in a more ad hoc manner, for instance through visits by local birdwatchers or BirdLife Partner staff.

Table 1. Examples (not comprehensive) of variables assessed on Important Bird Area monitoring forms.

\section{State}

Habitat area

Habitat quality

Populations of bird species for which Important Bird Area is listed

Pressure

Agricultural intensification/expansion

Burning of vegetation

Deforestation (commercial)

Forest grazing

Industrialization/urbanization/infrastructure/intensified forest management

Recreation/tourism

Unsustainable exploitation

Response

Percentage of Important Bird Area under legal protection

Number of Site Support Groups

Development of action plan

Resource use controls/quotas

Number of conservation staff and volunteers

Conservation projects/actions: implemented

Environmental Impact Assessments

Scores relate to trends since the previous assessment, ranging from -3 (major deterioration) to +3 (major improvement). 
The central IBA monitoring unit described above has responsibility for checking and compiling the information submitted on forms, and adding this to whatever is already available from other sources (for example, published or unpublished reports or newspaper articles). Based on all this information, overall improvement or deterioration is assessed as a simple score, and a rating filled in for each site to cover state, pressure and response. This overall score is informed by the scores on the forms, but is not necessarily identical to them.

The information used for scoring will often be very simple and non-quantitative. The system is intended to be adequate to capture gross changes in state (e.g., the destruction of part of a forest, the re-flooding of part of a wetland), in pressure (e.g., major new infrastructure or altered land-uses) or in response (e.g., gazettement as a protected area, inauguration of a local conservation group). This is sufficient to re-assess priorities for intervention and, in particular, to direct attention to new problems and issues. A heterogeneous set of information is turned into standardised, simple scores, which makes it easy to compile trends across sets of sites as required (by habitat, protection status, country, region and so on). Not all the possible indicators need to be assessed: it is sufficient to have information on one appropriate indicator for each of state, pressure and response.

\section{Detailed monitoring}

Detailed monitoring is more expensive and time-consuming than basic monitoring. Thus it is targeted at a sub-set of sites where it is likely to be both more useful and more feasible. Criteria might include the sites' priority for conservation action (Bennun and Njoroge 1999), the presence of particular threats that need tracking, ongoing conservation interventions whose impact needs assessment, and the presence of people who can do the monitoring - active SSGs, other volunteers or relevant Government agencies.

Detailed monitoring is designed for each site separately: there is no single, standard methodology. The indicators will vary according to the nature of the IBA and the conservation issues. This does not mean that 'anything goes': the rules of good monitoring design, including sound statistical sampling, must be followed. It is especially important that the variables relate to the conservation goals and management targets for the site. Suggestions for appropriate indicators, and examples of monitoring protocols for different African habitats, are given in Bennun (2001). As with basic monitoring, it is vital for sustainability that Government officers and SSGs institutionalise detailed monitoring in their work programmes.

How does detailed monitoring relate to basic monitoring? At an individual site, the variables tracked in detailed monitoring - for example, bird population counts - can be used directly to score trends for basic monitoring. While the main purpose of detailed monitoring is to assist adaptive management, once enough sites are covered it should also be very valuable for understanding the processes behind the patterns that basic monitoring reveals. 


\section{Resources required}

The resources required for an IBA monitoring programme are greatest in the early stages. Funds are needed to support training and awareness creation, and (for detailed monitoring) design of the sampling and equipping of staff and SSG members on the ground. Once the system is running smoothly, there are obviously real (though relatively modest) costs in sustaining it. If the system is fully institutionalised, then the costs of individuals' time, transport and subsistence should be covered from within institutional budgets. This is not necessarily easy to achieve, given that management authorities are often underresourced and that SSGs may have limited means of generating income. Basic monitoring requires very little extra investment of time and effort for those submitting the information. Even here, however, the costs of co-ordination must be met, and will include funds to buy and maintain appropriate computer hardware and software, to run the computer database and (ideally) a Geographic Information System; and a filing cabinet, for maintaining paper records. Resources are also needed to produce and circulate forms and reports, and for follow-up within the monitoring network, facilitation of the IBA National Liaison Committee's Monitoring Sub-committee and copying paper materials. For detailed monitoring, there will also be need to visit sites for follow-up training and quality checking.

\section{Testing the framework}

IBA monitoring is now underway in at least 10 countries in Africa, led by BirdLife Partners (Arinaitwe 2003). All these NGOs are working with a range of other national and local institutions to carry out basic monitoring and at least some detailed monitoring (often by incorporating ongoing waterbird counts) at priority sites. The system is furthest developed in Kenya, where the start-up phase has been supported through funding from the UK Government's Darwin Initiative.

There are 60 IBAs identified in Kenya, 25 of which lack formal protection. The Darwin Initiative project, 'Kenya's IBAs: Improving Monitoring, Management and Conservation Action' is led by the Royal Society for the Protection of Birds (BirdLife in the UK) and implemented through Nature Kenya (BirdLife in Kenya) in close collaboration with the National Museums of Kenya, Forest Department, Kenya Wildlife Service and other institutions on the IBA National Liaison Committee. The National Museums of Kenya leads on technical input and manages the monitoring data. The project aims to apply and improve the monitoring framework, so that the lessons learned from Kenya can help to inform what happens elsewhere. So far, work has concentrated on setting up the appropriate institutional structures, training of trainers, training in survey and monitoring techniques for SSG members and Government staff, and data compilation and management. 


\section{Basic monitoring}

In August 2004, Nature Kenya launched the second annual report based on the basic monitoring results. 'Kenya's IBAs: Status and Trends' is presented both as a 78-page compilation of new information, reported site-by-site, and as an 18-page summary for decision-makers (Ng'weno et al. 2004). The summary has also been sent to all those who contributed data. Monitoring information is now available for 49 sites, based on forms submitted by 144 site-based Government staff, SSGs and other knowledgeable individuals. Specific recommendations are made for the management of each site, as well as for nationallevel policy changes. Overall trend scores averaged across sites (Figure 2) show that the state of Kenya's IBAs is still deteriorating (despite improvements at certain sites), and pressures are still increasing. However, the level of response has risen substantially since the IBA directory was first published. Either this response remains inadequate, or there is still a lag before it starts to show effects (or both). This summary information is directly relevant for Kenya's national reporting to the Convention on Biological Diversity.

Production of the second annual report has highlighted some issues. First, the process of assigning overall scores needs to be made more robust and to involve more people. In particular, the monitoring focal points from key institutions need at least to review the scores assigned and look at how they have been justified. Changes in pressure or response do not necessarily imply changes in state, and clearer guidelines are needed for this, and for scoring the magnitude of change. Provision also needs to be made for scoring condition - the current level of state, pressure and response - as well as trend. A draft methodology for condition scoring has already been developed for testing.

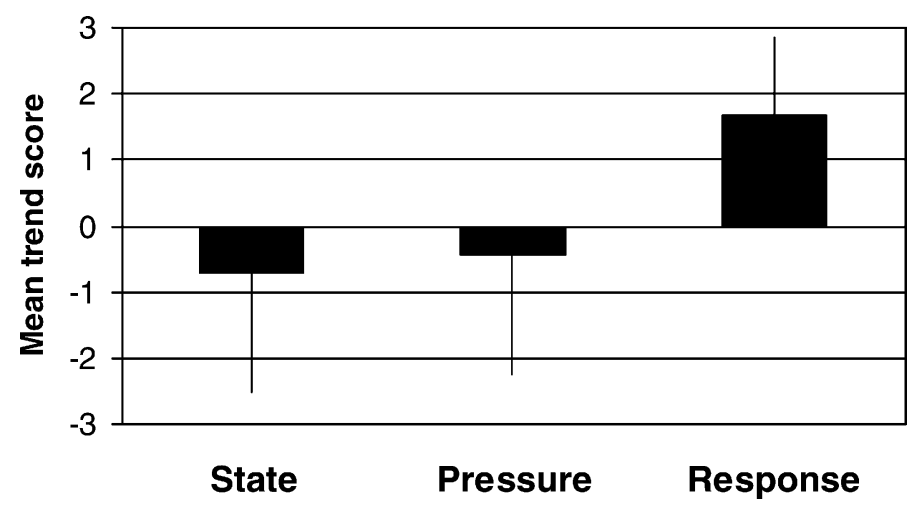

Figure 2. Trends (mean scores) for Kenya in Important Bird Area state, pressure and response from 1999 (when the national Important Bird Area directory was first published) to 2003. Data were adequate to score trends in 51 out of 60 sites. The bars show standard deviations. 


\section{Detailed monitoring}

Detailed monitoring by SSGs and/or Government field staff is now underway at six sites. The Kinangop Grasslands IBA provides an example. This 77,000 ha IBA covers the Kinangop Plateau, a tract of high land east of the central Rift Valley in Kenya. A relatively well-watered area, Kinangop is now densely settled by small-scale farmers. The plateau forms part of the Kenyan Mountains Endemic Bird Area (Stattersfield et al. 1998). It contains unique animals and plants, including Sharpe's Longclaw Macronyx sharpei, a threatened grassland bird species endemic to central Kenya (Muchai et al. 2002a). However, the biodiversity value of Kinangop has only recently been recognised (Bennun and Njoroge 1999). None of the grassland has any formal protection; all is privately owned, and it is fast disappearing. The underlying causes of this include population growth and consequent sub-division of large farms (Ndang'ang'a et al. 2002), and a complex set of socio-economic factors that are driving a shift from dairy farming towards cash-crop cultivation (Muchai et al. 2002b).

The Friends of Kinangop Plateau (FKP), a Site Support Group, has four sub-groups in different sectors of the 77,000 ha IBA. The SSG members are local residents, most of them landowners and farmers, who are concerned at the changes they see in the environment around them. Many have also developed a strong interest in birds and birdwatching.

Since mid-2001, starting with the Murungaru sub-group, FKP has been carrying out grassland monitoring to answer the following questions:

- Where are the plateau's special birds?

- How are their populations changing over time?

- How is their habitat changing over time?

Each sub-group has now set up a monitoring sub-committee with a monitoring focal person. The monitoring uses a set of sample plots (fenced fields) and is carried out twice each year, in the wet (initially June/July, now August) and dry (February) seasons. The main focus is on Sharpe's Longclaw, which is sensitive to loss or alteration of grassland (Muchai et al. 2002a). In each field the observers count (by flushing) Sharpe's Longclaws and other grassland birds, make a simple assessment of grassland quality using reference photographs, and record any major land-use changes (e.g., all or part of a field being ploughed up for cultivation). Data are recorded on standard data sheets.

Each sub-group is now tracking 40 permanent sample plots, 20 of these initially with high-quality grassland, 10 with poor-quality grassland and 10 cultivated for various crops (and therefore not used by grassland birds). Staff of the National Museums of Kenya and Nature Kenya have helped with sample design and carried out field training and follow-up supervision for all the sub-groups. Several group members have also attended national training courses on the principles of monitoring. It is the task of each group's moni- 
toring focal person to ensure that copies of data sheets are sent to the Nature Kenya/NMK database, while keeping the originals on file in the sub-group office.

At the end of August 2004, the longest-established sub-group (at Murungaru) was about to complete its third year of data collection. Between 12 and 20 group members have been involved in each monitoring session, with a core team of around six people taking part every time: these are experienced field observers and able to collect data consistently and accurately. Other members have been involved less regularly but have worked under supervision by the experienced monitors. The methodology laid down when the monitoring started is simple, has worked well, and has not needed refinement. After the first session, improvements were necessary in the design of the monitoring forms, and problems have also been corrected (through further training) concerning timing and consistency of plot coverage, assessment of area and identification of additional grassland bird species. Only 11 grassland plots have been counted in all six monitoring sessions (from the wet season count in June 2001 to the dry season count in February 2004), illustrating the problem of consistency. The total number of Sharpe's Longclaws in these plots was stable across years, though higher in the wet season (32-38 birds) than the dry (16-20 birds). Less encouraging, in this 30 -month period $17.3 \%$ by area of the 24 grassland study plots for which data are available (comprising 533.5 ha intially) was converted to cultivation - a rate of about $7 \%$ per year. This high rate of loss has helped to stimulate and justify funding for the purchase of a Sharpe's Longclaw reserve in the Murungaru area, to be managed by FKP.

At Kinangop, it has taken time to dispel the feeling that monitoring was being done 'for' Nature Kenya and the National Museums, and not because this was the group's own priority activity. Resolution of this has not been helped by slow and patchy feedback of monitoring results. Reporting was given inadequate priority over other project activities, and was hampered by staff turnover at the National Museums and difficulties in data interpretation. Monitors also feel they should be compensated, at least in part, for the time and effort involved (working through the whole set of plots can take up to 10 days). It is inappropriate for Nature Kenya to pay them and FKP still lacks the resources to do so. This problem has been eased somewhat by making the monitoring sessions more of a social event: after a morning's fieldwork the monitoring team visits the home of a nearby FKP member for lunch. FKP members are happy to provide this hospitality and there are sufficient of them that the individual burden is light - a visitation once every several years. While this makes the monitors feel better valued, and provides them with lunch after a long morning assessing the sample plots, it is not a complete solution. In the long run, it seems the only workable approach is to compensate the monitoring team at an appropriate level (not necessarily the full value of their time if spent on other work), agreed within the group and from funds that the group itself has raised. 


\section{Discussion}

Implementing the IBA monitoring framework in just one country, Kenya, has at times seemed a Sisyphean task - the boulder never quite seemed to get to the top of the hill and start rolling away by itself. After several years of effort, however, IBA monitoring is starting to become properly institutionalised in Kenya. It is clear that, even once established, monitoring will require continued central co-ordination, analysis and reporting. The resources needed for this are relatively small but must be found in-country, an additional and challenging step in the institutionalisation process.

Some lessons learned since the framework was adopted include the following:

- Participatory monitoring has important advocacy and education value, both for those taking part and for other local residents. It helps build awareness, interest, involvement and individual and institutional capacity in many useful ways. It needs to be fun.

- There is need for strong and ongoing coordination support. In particular, quick and regular feedback, appropriately pitched, is vital for maintaining morale and enthusiasm. It also helps show how value is added when data are incorporated into a larger dataset.

- Institutionalisation of the process is vital. However, it takes time and active effort. There is a gap between monitoring starting and meaningful results being generated, where it can be hard work to maintain momentum. The assumption that organisations want and need monitoring information may also not always be valid. Ownership of both the data and the process are important for institutionalisation. Details such as the logos and addresses on basic monitoring forms can make a difference.

- It is important to have feedback mechanisms that act to evaluate and improve the monitoring process itself. In Kenya there are several formal and informal structures that make this easier, including a cross-institutional monitoring implementation team, a Darwin project steering committee, the IBA National Liaison Committee and SSG site monitoring committees.

Is the IBA monitoring approach working? If so, how reliable and useful are the data? The Kenyan experience suggests that basic monitoring, once established, does produce useful results (at both the site and national level) for relatively little cost. In the 2004 national IBA assessment, specific recommendations were put forward for many sites, new threats flagged and overall trends identified. This information is directly relevant to local and national policy and planning, and to reporting against international commitments. Progress with detailed monitoring, carried out mainly by SSGs, also looks promising, but it is too early to make a definitive judgement.

Another crucial element of the IBA monitoring framework remains as yet unproven - the feedback loop from data and analysis to action on the ground. Institutionalisation should help ensure that results are indeed translated into 
management practice and policy reform (see Danielsen et al. 2005 (this issue)). However, this remains a challenge - as it is for any monitoring system. In Kenya, training in management planning is an additional activity under the Darwin Initiative, and the IBA management plans now being prepared are building in this feedback loop. Nature Kenya is also leading a review of priorities for conservation action among IBAs (Bennun and Njoroge 1999) in the light of the 2004 status report.

A concern often raised about participatory monitoring is whether the results can be scientifically validated (e.g., Uychiaoco et al. 2005 (this issue)) For IBA monitoring there are two aspects to this. The methods used in detailed monitoring at Kinangop (and at five other IBAs in Kenya) are simple, robust and inexpensive, but they are designed by scientists, as is the sampling regime. The issue thus boils down to whether the data are being collected accurately and reliably. Training and supervisory visits show that problems do crop up, but that these are minor and easily corrected. Nevertheless a more detailed analysis is now planned of the data collected from all six sites, which should help to pinpoint any anomalies.

Basic monitoring is less straightforward to validate. One test, which has not yet been carried out, would be to assess changes inferred from the monitoring forms against those from detailed monitoring (or other independent data). Inconsistent evaluation is clearly a potential problem. The need is now recognised for clearer scoring guidelines and a more rigorous and consultative assessment process. A new scoring system, now ready for testing, provides tighter definitions and will allow scoring of both status and trends.

The present IBA monitoring framework focuses on biodiversity. However, the same locally-based approach could readily be used for broad-brush assessment of the goods and services produced by an IBA, and of other variables related to sustainable livelihoods. This has not yet been done. However, BirdLife is developing a set of simple indicators, for measurement by SSGs, that can show change in the many dimensions of poverty (human, socio-cultural, political, protective and economic: OECD 2001). Adding these dimensions would make the IBA monitoring framework valuable for assessing progress not just towards the 2010 biodiversity target but also the Millennium Development Goals (United Nations 2000).

\section{Acknowledgements}

This paper is an expanded version of a presentation we were invited to make at a symposium on locally-based monitoring in Denmark in April 2004 (www.monitoringmatters.org). The symposium was organized by the Nordic Agency for Development and Ecology (NORDECO, Denmark), and the Zoology Department of Cambridge University (UK). Development of the Africa IBA monitoring framework was supported by the GEF/UNDP project 'African NGO-Government partnerships for sustainable biodiversity action'. 
We are grateful to many colleagues in BirdLife for shared experience, discussion and insights, especially J. Arinaitwe, C. Bowden, L. Fishpool, A. Kiragu, S. Musila, J. Musina, S. Nagy, N. Otieno, W. Wanyoike, members of 'Friends of Kinangop' Murungaru sub-branch, and all the participants in the August 2003 workshop 'IBA monitoring in Africa'. This workshop was supported by the Netherlands Ministry of Agriculture, Nature and Food Quality (LNV) and the Directorate-General for International Cooperation, Netherlands Ministry of Foreign Affairs (DGIS). The project 'Kenya's Important Biodiversity Areas: improving monitoring, management and conservation action' is funded through the UK Government's Darwin Initiative for the Survival of Species. Thanks to A. Balmford, N. Burgess, F. Danielsen and two anonymous referees for comments that helped to improve this paper.

\section{References}

Andrianandrasana H., Randriamahefasoa J., Durbin J., Lewis R. and Ratzimbazafy J. 2005. Participatory ecological monitoring of the Alaotra wetland in Madagascar. Biodivers. Conserv. 14: 2757-2774.

Arinaitwe J. 2003. IBA Monitoring in Africa. Proceedings of the IBA Monitoring Workshop, Naivasha 6-8 August 2003. BirdLife International, Nairobi, Kenya.

Balmford A., Green R.E. and Jenkins M. 2003. Measuring the changing state of nature. Trends Ecol. Evol. 18: 326-330.

Bennun L.A. 2001. Long-term monitoring and the conservation of tropical wetlands: high ideals and harsh realities. Hydrobiologia 458: 9-19.

Bennun L. 2002. Monitoring Important Bird Areas in Africa. A Regional Framework. BirdLife International, Cambridge, UK.

Bennun L. and Njoroge P. 1999. Important Bird Areas in Kenya. Nature Kenya, Nairobi, Kenya. BirdLife International. 2004a. State of the World's Birds: Indicators for our Changing World. BirdLife International, Cambridge, UK.

BirdLife International. 2004b. Working Together for Birds and People. Delivering Solutions for our Changing World. BirdLife International, Cambridge, UK.

Danielsen F., Mendoza M.M., Alviola P., Balete D.S., Enghoff M., Poulsen M.K. and Jensen A.E. 2003. Biodiversity monitoring in developing countries: what are we trying to achieve? Oryx 37 : 407-409.

Danielsen F., Jensen A.E., Alviola P.A., Balete D.S., Mendoza M.M., Tagtag A., Custodio C. and Enghoff M. 2005. Does monitoring matter? A quantitative assessment of management decisions from locally-based monitoring of protected areas. Biodivers. Conserv. 14: 2633-2652.

Dodman T. 1997. A Preliminary Waterbird Monitoring Strategy for Africa. Wetlands International Publication 43. Wetlands International, Wageningen, The Netherlands.

Roberts R.L., Donald P.F. and Fischer I.J. 2005. Project Kagu: developing a web-based data collection system for the global monitoring of bird distribution and abundance. Biodivers. Conserv. 14: 2807-2820.

Eken G., Bennun L., Brooks T.M., Darwall W., Fishpool L.D.C., Foster M., Knox D., Langhammer P., Matiku P., Radford E., Salaman P., Sechrest W., Smith M.L., Spector S. and Tordoff A. Key biodiversity areas as site conservation targets. BioScience 54: 1110-1118.

Fishpool L.D.C. and Evans M. (eds), 2000. Important Bird Areas in Africa and Associated Islands: Priority Sites for Conservation. BirdLife Conservation Series 11. Pisces Publications, BirdLife International, Newbury, UK, Cambridge, UK.

Gray M. and Kalpers J. 2005. Ranger-based monitoring in the Virunga-Bwindi region of East-Central Africa: a simple data collection tool for park management. Biodivers. Conserv. 14: 2723-2741. 
Gregory R.D., Noble D., Field R., Marchant J., Raven M. and Gibbons D.W. 2003. Using birds as indicators of biodiversity. Ornis Hungarica 12-13: 11-24.

Muchai M., Lens L. and Bennun L. 2002a. Habitat selection and conservation of Sharpe's Longclaw (Macronyx sharpei), a threatened Kenyan grassland endemic. Biol. Conserv. 105: 271-277.

Muchai M., Bennun L.A., Lens L., Rayment M. and Pisano G. 2002b. Land-use and the conservation of Sharpe's Longclaw Macronyx sharpei in central Kenya. Bird Conserv. Int. 12: 107-121.

Ndang'ang'a P.K., du Plessis M.A., Ryan P.G. and Bennun L.A. 2002. Grassland decline in Kinangop Plateau, Kenya: implications for conservation of Sharpe's Longclaw (Macronyx sharpei). Biol. Conserv. 107: 341-350.

Ng'weno F., Otieno N. and Matiku P. (eds), 2004. Kenya's Important Bird Areas: Status and Trends 2004. Nature Kenya, Nairobi, Kenya.

OECD. 2001. The DAC Guidelines: Poverty Reduction. Organisation for Economic Development and Co-operation, Paris, France.

Poulsen M.K. and Luanglath K. 2005. Projects come, projects go: lessons from participatory monitoring in southern Laos. Biodivers. Conserv. 14: 2591-2610.

Pretty J. and Smith D. 2004. Social capital in biodiversity conservation and management. Conserv. Biol. 18: 631-638

van Rijsoort J. and Jinfeng Z. 2005. Participatory resource monitoring as a means for sense-making and social change in Yunnan, P.R. China. Biodivers. Conserv. 14: 2543-2573.

Royal Society. 2003. Measuring Biodiversity for Conservation. Policy Document 11/03. Royal Society, London, UK.

Saterson K.A., Christensen N.L., Jackson R.B., Kramer R.A., Pimm S.L., Smith M.D. and Wiener J.B. 2004. Disconnects in evaluating the relative effectiveness of conservation strategies. Conserv. Biol. 18: 597-599

Sheil D. 2001. Conservation and biodiversity monitoring in the tropics: realities, priorities and distractions. Conserv. Biol. 15: 1179-1182.

Stattersfield A.J., Crosby M.J., Long A.J. and Wege D.C. 1998. Endemic Bird Areas of the world. Priorities for Conservation. BirdLife Conservation Series No. 7. BirdLife International, Cambridge, UK.

Topp-Jørgensen E., Poulsen M.K., Lund J.F. and Massao J.F. 2005. Community-based monitoring of natural resource use and forest quality in montane forests and miombo woodlands in Iringa District, Tanzania. Biodivers. Conserv. 14: 2653-2677.

United Nations. 2000. Resolution Adopted by the General Assembly. 55/2 Millennium Declaration. United Nations, New York, USA.

United Nations. 2002. World Summit on Sustainable Development: Johannesburg Plan Implementation. United Nations, New York, USA.

Uychiaoco A.J., Arceo H.O., Green S.J., de la Cruz M.T., Gaite P.A. and Aliño P.M. 2005. Monitoring and evaluation of reef protected areas by local fishers in the Philippines: tightening the adaptive management cycle. Biodivers. Conserv. 14: 2775-2794.

Yoccoz N.G., Nichols J.D. and Boulinier T. 2001. Monitoring of biological diversity in space and time. Trends Ecol. Evol. 16: 446-453. 